\title{
Review Article \\ Dietary Treatment Options for Depression among Diabetic Patient, Focusing on Macronutrients
}

\author{
Fahimeh Haghighatdoost ${ }^{1}$ and Leila Azadbakht ${ }^{1,2}$ \\ ${ }^{1}$ Food Security Research Center, Isfahan University of Medical Sciences, Isfahan 21871, Iran \\ ${ }^{2}$ Department of Community Nutrition, School of Nutrition and Food Science, Isfahan University of Medical Sciences, \\ Isfahan 21871, Iran \\ Correspondence should be addressed to Leila Azadbakht; azadbakht@hlth.mui.ac.ir
}

Received 18 July 2013; Revised 28 August 2013; Accepted 29 August 2013

Academic Editor: Hiroshi Okamoto

Copyright (C) 2013 F. Haghighatdoost and L. Azadbakht. This is an open access article distributed under the Creative Commons Attribution License, which permits unrestricted use, distribution, and reproduction in any medium, provided the original work is properly cited.

\begin{abstract}
There is a bidirectional adverse association between diabetes and depression. The odds for experiencing depressive symptoms in diabetic patients are two times more than nondiabetic persons, and depression is an independent predictor for the onset of diabetes. However, depression has been approximately unrecognized and untreated in two-thirds of diabetic patients, which may lead to worsened diabetes complications. A cornerstone strategy for managing depression among diabetic patients is the use of diet to improve both health problems. Because of similar pathophysiology for chronic diseases and depression, it seems that similar dietary recommendations could be useful. However, few studies have been conducted among diabetic patients. Regarding the complications of diabetes such as renal diseases and coronary heart diseases, the proper range of various macronutrients should be clarified in depressed diabetic patients as well as the proper type of each macronutrient. In this paper, we reviewed the available data on the treatment of depression in diabetic patients.
\end{abstract}

\section{Introduction}

Major depression is a high prevalent comorbid in patients with type 1 or 2 diabetes $[1,2]$. The odds for experiencing depressive symptoms in diabetic patients is two times more than nondiabetic persons, independent of sex, type of diabetes, subject source, or assessment method for depression [1]. Furthermore, the prevalence of depression is higher among diabetic women than men (28\% versus $18 \%$ ) [1]. Depression is considered as an independent predictor for the onset of diabetes $[3,4]$. Conversely, the presence of a depressive history during lifetime increases the risk of diabetes in later-life cycle [5-9], and there is a bidirectional adverse association between diabetes and depression.

The exact mechanisms underlying the relationship between depression and diabetes have not been established yet. Suggested mechanisms by which anxiety and depression increased the risk of diabetes are alterations in insulin signaling in the brain, activation of proinflammatory pathways, and/or distress-induced upregulation of counter- regulatory hormone systems like glucocorticoid [10, 11], which could impair insulin sensitivity. Another possible mechanism may be related to the effect of depression on behaviors and lifestyle. It has been shown that depressed persons are more likely to be physically inactive and central and/or general obese and have unhealthy eating habits, poor diet, and sedentary lifestyle [12-15], which is associated with increased risk of coronary heart diseases and diabetes. Elevated serum C-reactive protein (CRP), homocysteine, and higher 24-hour urine free cortisol may provide another additional mechanism whereby depression increases the risk of chronic disease such as CHD and diabetes [16-20].

Despite the high prevalence rate of depression among diabetic patients, it has been approximately unrecognized and untreated in two-thirds of diabetic patients [21]. Additionally, because of the severity and chronic course of depression in diabetic patients, $80 \%$ of them may experience depression relapse even after successful treatment [22]. Once chronic medical illness appears, comorbid depression increases the burden of symptoms and functional disability [23, 24]. 
Untreated depression is associated with worsened diabetes complications such as retinopathy, nephropathy, neuropathy, sexual dysfunction and coronary heart disease $[25,26]$, poorer glycemic control [27], and higher insulin level [28]. Furthermore, depressed diabetic patients were less tended to adhere dietary recommendations, physical activity program, self-care, and medication regimens [29-31]. Depression has some other disadvantage for diabetic patients: the costs of medical therapies are 4.5 times higher for depressed diabetic than nondepressed [31], the odds of experiencing functional disability are 7.15 times higher among depressed-diabetics than nondepressed ones [32], and depressed-diabetic patients have 2.3 times higher risk for mortality compared with diabetic patients without depression [33]. It has been shown that $54 \%$ of patients with both problems had early mortality [34]. Therefore, the important health outcomes of depression in diabetic patients necessitate the optimal medical care to improve both health problems. It has been suggested that if glycemic control was not achieved by routine medical therapies, depression should be noted as a potential cause [35].

A cornerstone strategy for managing depression among diabetic patients is the use of diet to improve both health problems. Although the association of dietary intake and depression is a novel field which emerged during last ten years, the similarity between the pathophysiology of chronic diseases and depression may need some similar dietary recommendations. Most of available studies have been conducted among depressed patients without diabetes, and few studies have been conducted among diabetic patients. In this paper, we aimed to review the present studies regarding the dietary approach for treating depression among diabetic patients.

\section{Methods}

In order to search the relevant English and non-English published papers we used the online databases of PubMed, ISI Web of Science, SCOPUS, Science Direct, and EMBASE for the period from January 2000 to May 2013. The keywords used in our search strategy were depression, depressive, depressed, diabetes mellitus, diabetic patients, diet, macronutrients, fat, protein, carbohydrate, nutrition, and food. We found 410 papers which is published between 1965 and 2013, but some of them were excluded because they were not conducted among diabetic patients or they were not related to dietary intakes especially macronutrients. We found only 7 studies which conducted among depressed and diabetic patients. Two studies assessed the effect of protein intake, 2 studies assessed the add-on EPA effect, 1 study assessed the effect of dietary carbohydrate, and 2 cross-sectional studies assessed the association between carbohydrate intake and depression mood. One of these cross-sectional studies was specifically conducted among diabetics, but another study was conducted among healthy and diabetic patients. We also summarized the most important studies that were reviewed in the current paper in Table 1.

\section{Dietary Carbohydrate}

Carbohydrate intake seems to be an important factor in the management of depression and diabetes. Depressive symptoms are associated with lower consumption of vegetables and fruits [43], while overeating of high glycemic index (GI) foods is a routine coping in depressed and stressful patients [44-46]. The adverse effects of high GI on glycemic control and insulin resistance have been shown previously [47-49]. Therefore, in order to achieve a better glycemic control in diabetic patients, the management of carbohydrate intake may play a noteworthy role. Very few studies were conducted to assess either the effect of low or high consumption of carbohydrate or the effect of glycemic index and glycemic load (GL) on depressive symptoms in diabetic patients [3638]. Carbohydrate consumption is associated with higher secretion of insulin which facilitates the transport of tryptophan in the brain and leads to higher synthesis of serotonin $[46,50,51]$. Thereby, higher GI and GL carbohydrate could potentially have more beneficial effects on depressive symptoms. However, two limitations remain which should be noted. First, higher glycemic index diets may be associated with lower diet quality and the lower intake of some key nutrients for depression such as magnesium, riboflavin, and dietary folate equivalents (DFE) [52]. Furthermore, higher GI index diets are mainly recognized with lower consumption of some nutrient-dense foods including vegetables, fruits, and fiber [53]. Poor diet quality and food choices, therefore, would be expected to adversely affect depressive symptoms. Another limitation is related to glycemic control. Although some studies showed that the amount of carbohydrate is the main concern rather than GI or GL in diabetic patient's diet $[54,55]$, others yet advice to prescribe a low-GI and GL diet for diabetics [47-49]. The entry of tryptophan into the brain is also related to its plasma concentration to the sum of the other large neutral amino acids (Trp/LNAAs ratio) (LNAAs: tyrosine, phenylalanine, leucine, isoleucine, valine, and methionine) [56]. High GI carbohydrates increase insulin levels and whereby thus stimulate the selective uptake of LNAAs by muscles and increase the Trp/NLAAs ratio [57]. It has been shown that elevated ratio of Trp/NLAAs which is achieved by carbohydrate consumption improves performance and mood under the stress [58].

A randomized clinical trial compared a low GI diet versus ADA diet in diabetic patients [36]. Both diets were similar in their carbohydrate, protein, saturated fatty acids (SFAs), and cholesterol content. Two prescribed diets contained $55 \%$ carbohydrate, but in low-GI diet participants were encouraged to consume low-GI carbohydrate, while in ADA diet, all carbohydrate foods were treated the same. After 12 months, participants in ADA group consumed significantly more carbohydrate but decreased GI. Although the GI did not differ significantly between two groups ( 80 in the ADA versus 76 in the low GI; $P=0.07$ ), dietary GL was significantly lower in low-GI group compared with ADA after 6 months (97 versus 141; $P=0.02$ ). Both diets showed significant improvement in metabolic markers after 12 months. In 


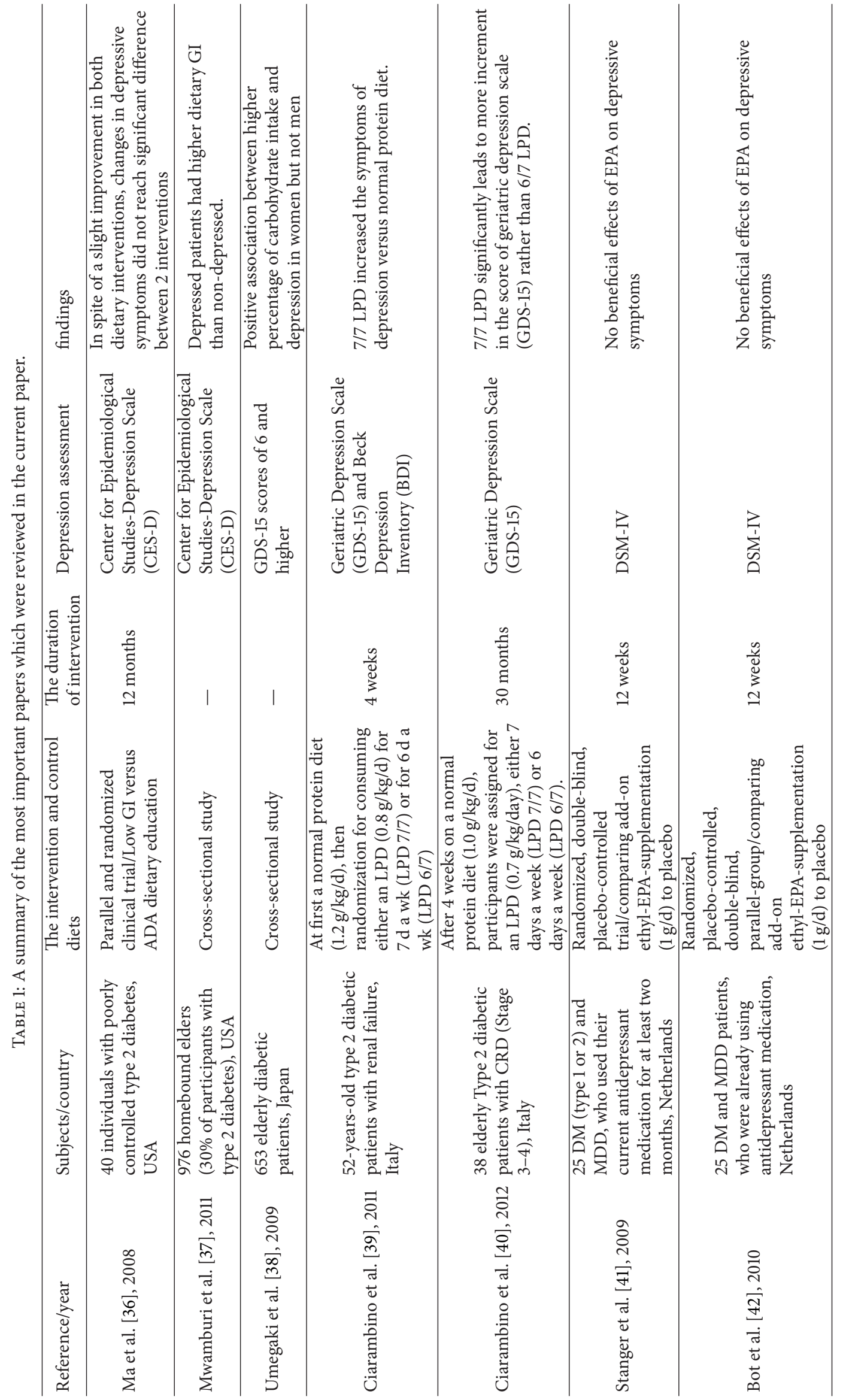


spite of a slight improvement in both dietary interventions, changes in depressive symptoms did not reach significant difference comparing the two interventions.

Umegaki et al. [38] in a cross-sectional study on elderly diabetic patients showed that higher percentage of carbohydrate intake is positively associated with depression in women but not men. Another cross-sectional study on 976 homebound elders (30\% of participants with type 2 diabetes) assessed the relationship between dietary GI and depression [37]. The findings of this study suggested that despite similar amount of carbohydrate consumption by both depressed and nondepressed, GI and serum insulin levels were significantly higher in depressed patients than nondepressed $(P$ values $=0.003$ and 0.05 , resp.). Patients receiving antidepressant agents (specially selective serotonin reuptake inhibitors (SSRI)), had lower GI and GL compared with who did not $(P=0.002$ and 0.03 , resp.). The association between dietary GI, GL, the amount of consumed carbohydrate and depression are also inconsistent among nondiabetic patients [59-61]. Some reports showed that higher dietary GL decreases the risk of depression $[59,60]$, while others failed to reach such findings [61]. However, most of available studies have not linked dietary GI to depression [59, 61].

Totally, few studies were conducted among diabetic to assess the effect of dietary carbohydrate on depression symptoms. Available studies are inconsistent. While a clinical trial did not approve the effect of GI and GL on depression, observational studies showed significant association. Moreover, benefits and disadvantages of low-carbohydrate diets are still on debate and should be noted in the treatment of depression. While some clinical trials have advocated the beneficial effects of low carbohydrate diets (LCD) on metabolic markers and weight loss, their long term effects on psychological features have been poorly studied. Some shortterm studies have shown that dietary composition could not significantly affect mood state [62-64]; however, there are some long-term evidences that showed adverse effects of LCD on mood state compared with low fat diet (LFD) among nondiabetic patients. Halyburton et al. showed that both LCD and LFD improve mood after 8 weeks [65], but following this study for 52 weeks dispute this finding. Brinkworth et al. showed that although decreased scores of depression and depression-dejection were stable over time for LFD, they returned toward baseline values for LCD after 52 weeks [66]. The adverse effects of LCD may be due to disturbed synthesis of serotonin or Brain-Derived Neurotrophic Factor (BDNF). More studies should be conducted to illustrate the beneficial and adverse effects of LCD on psychological function.

\section{Dietary Protein}

Renal disease, another complication of diabetes, has been widely claimed that is associated with depression [67-69]. Low protein diet $(0.6-0.8 \mathrm{~g} / \mathrm{kg})$, the common treatment of chronic renal disease, has some beneficial effects on the progression of renal failure, inflammatory makers levels and coagulation proteins such as fibrinogen in nephropathicdiabetic patients [70-76].
A noteworthy aspect regarding the protein consumption and depression is related to its effect on Trp/LNAA. It has been shown that a high protein meal decreases the serum level of Trp while increases LNAAs and; therefore, decreases the Trp/LNAA ratio [56]. Hence, a low protein diet may have some beneficial effect on Trp/LNAAs, the Trp transmission into the brain and the synthesis of serotonin. However, a low protein diet provided lower amount of tryptophan which could interact with the beneficial effects of low protein diet. The effect of dietary protein intake on depression is unclear, and only two studies assessed the effects of low protein diet on depressive symptoms among diabetic patients in short and long term $[39,40]$.

In a randomized clinical trial, Ciarambino et al. [39] compared the effect of a 6-day/week low protein diet $(6 / 7$ LPD, with a day/week normal protein diet) with a 7-day/week one (7/7 LPD), after 4 weeks on young-old type 2 diabetic patients. LPD contained $0.8 \mathrm{~g} / \mathrm{kg}$ protein which more than $65 \%$ of ingested protein was provided by high biological value. Before the beginning of study, all patients consumed a normal protein diet $(1.2 \mathrm{~g} / \mathrm{kg})$ for at least 4 weeks. Normal protein diet contained $50 \%$ carbohydrate and $25 \%$ fat, while in low protein diet $35 \%$ of total energy intake was provided by fat (especially unsaturated fatty acids). The results of study showed that 7/7 LPD increased the symptoms of depression versus normal protein diet. In the other long term study [40], Ciarambino et al. followed up these patients for 30 months. At the end of study, 7/7 LPD significantly leads to more increment in the score of geriatric depression scale (GDS-15) rather than 6/7 LPD. The probable reason of such findings may be related to the lower content of thiamine, folate, iron, and Trp which induces cognitive changes consistent with depressive mood [77-79]. The proportion of dietary macronutrients must also be taken into account when interpreting the findings. On the other hand, the beneficial effects of normal protein diet and 6/7 LPD rather than 7/7 LPD might be due to the higher proportion of dietary fat, especially unsaturated fatty acids. We found very limited studies among depressed patients without diabetes which assessed the effect of different amount of protein consumption on depressive symptoms. The results of a 10year follow-up study showed that higher protein intake is associated with lower but higher risk of depression among men and women, respectively [80]. One clinical trial could not find any significant difference between the effect of highcarbohydrate (En\% Protein/Carbohydrate/Fat $=6 / 64 / 30$ ) and high protein $($ En\% Protein/Carbohydrate/Fat $=65 / 5 / 30)$ meals on psychological mood [81]. The results of our search did not show any study in relation to assess the effect of various types of protein on depression. More studies are necessary to illustrate the exact and clear effect of the amount and kind of dietary protein intake on depressive symptoms among diabetic (and nondiabetic) patients.

\section{Dietary Fat}

Dietary fat intake has a strong role in determining stress oxidative and inflammation. Furthermore, both diabetes 
mellitus and depression are associated with lower $n-3$ polyunsaturated fatty acids (n-3 PUFA) concentrations [82-84] and disturbed lipid profile [85-87]. A hypothesis for explaining the increased prevalence of obesity, diabetes, and their comorbidities such as depression during last years, is related to increased intake of saturated fatty acid (SFA) and the ratio of n-6/n-3 PUFA [88]. The favorable effect of n-3 PUFA consumption has been approved either by epidemiological studies which assessed fish consumption and or by ones which assessed the red blood cell concentrations of $n-3$ PUFA [89-93]. However, the results of a meta analysis on 28 randomized and placebo controlled clinical trial showed that the efficacy of n-3 PUFA in depression is related to eicosapentaenoic acid (EPA) not docosahexaenoic acid (DHA) [94].

We did not find any epidemiological study regarding the association between n-3 PUFA consumption and depression among diabetic patients. We just find two clinical trials which assessed the effects of EPA consumption on depressive symptoms in diabetic $[42,95]$. A randomized clinical trial by Bot et al. [42] did not confirm the beneficial effects of add-on supplementation of EPA (1 g/d) on depressive symptoms in diabetic patients, after 12 weeks. However, because of the strong link between EPA intake and some similar biological disturbances in diabetes and depression, such as hypothalamus-pituitaryadrenal (HPA)-axis hyperactivity [4] and one-carbon-cycle alterations [41], authors also assessed the effect of EPA on more biological markers [95]. They did not find any significant effects of EPA supplementation on oxidative stress, inflammatory, or one-carbon-cycle parameters compared with placebo. In this study, EPA consumption increased serum content of DHA, HDL-C and total cholesterol and decreased plasma concentration of arachidonic acid.

The relationship between other types of fatty acids and depression has been poorly studied. There is some evidence which may link depression and SFA as well as trans fatty acids (TFA) intake [96, 97]. First, the simultaneous increment in the prevalence of depression and dietary changes toward "western dietary pattern," which is rich in SFA and TFA, might be one of the most important evidence. Second, there are similar pathogenesis for several chronic diseases and depression. The adverse effects of SFA and TFA on coronary heart diseases and diabetes mellitus have been well established. Because of similar pathophysiology for such chronic diseases and depression, the harmful effects of SFA and TFA could be also considered for depression. However, few studies assessed the association between SFA and TFA and depression. In a cohort study, Sánchez-Villegas et al. [96] showed that persons in the highest quintile of TFA had $48 \%$ increment in depression risk compared with first quintile, with a significant linear trend. They also showed that PUFA intake is inversely associated with depression, but n-3, n6 , and n-3 from fish and n-3:n-6 were not associated with depression. In this study, a marginal significant inverse doseresponse association was found for MUFA consumption. Most of observational and interventional studies among nondiabetic patients confirmed the health benefit of $n-3$ fatty acids on depressive symptoms [98-101]. However, the published literature is conflicting. For example, in one study, the inverse association between higher consumption of fish, DHA, EPA, and depression were observed only in boys but not girls [98]. Other study found a cross-sectional, but not longitudinal, association between depression and n-3 consumption [101]. The results of a clinical trial did not confirm the beneficial effects of $n-3$ supplementation on amelioration of depressive symptoms [102]. There are such discrepancies for other fatty acids. Some investigators found a link between the erythrocytes concentration of TFA, short chain SFA, short chain MUF (lower than 18 carbons), and depression [84, 103], while other study showed higher concentration of SFA decreases the risk of depression [103]. Assies et al. found lower concentration of long chain SFA, MUFA and PUFA in the erythrocyte of patients with depression in comparison with nondepressed [84].

The beneficial effects of MUFA, and PUFA intake on depression might be related to their association with inflammation. Higher levels of inflammatory markers in depressed persons may reduce serum tryptophan level and impair neurotransmitter metabolism by inhibition of the gene expression of Brain-Derived Neurotrophic Factor (BDNF) $[104,105]$. Lower level of BDNF has been shown in depressed patients [106]. Therefore, beneficial subtypes of fatty acids could improve depressive symptoms by modulating serum levels of inflammatory markers. Furthermore, endothelium is the source of BDNF synthesis and secretion [107], and TFA promote endothelial dysfunction [108] and therefore consequently lead to lower level of BDNF. Beside the types of fatty acids, the amount of fat consumption is another determinant of depression. It has been shown that low fat diets could adversely affect mood $[109,110]$. However, to the best of our knowledge, there is no study assessing the effect of dietary fat amount on depressive symptoms among diabetic patients.

\section{Dietary Patterns}

Depression is associated with unhealthy food choices. Several studies showed higher consumption of unhealthy foods and lower consumption of fruits and vegetables in depressed mood [111]. Although dietary patterns and diet quality are a novel area of attention in the lifestyle-mental health research field, there is no study in this field among diabetic patients. The results of Whitehall II prospective cohort study showed that "whole food" pattern (rich in vegetables, fruits, and fish) was inversely associated with depression, while "processed food" pattern (rich in sweetened desserts, fried food, processed meat, refined grains, and high-fat dairy products) showed a direct association with depression in middle-aged population [112]. In this population the prevalence of diabetes mellitus was significantly higher among depressed persons compared with nondepressed ones (5\% versus $2.5 \% ; P=$ 0.003 ). However, another study among Japanese did not show any significant association between depression and various dietary patterns (including "Healthy," "Western," "Bread and confectionery," and "Alcohol and accompanying") [113]. Furthermore, in this study, various dietary determinants of depression such as energy intake, vitamin B2, B6, B12, and 
n-3 PUFA did not significantly differ between depressed and nondepressed. In the GAZEL cohort study, after 1-year followup [114], Le Port et al. reported that men who were in the highest quartile of low-fat, western, high snack, and high fat-sweet diets and women who were in the highest quartile of low-fat and high snack were more likely to be depressed versus the lowest quartile. Conversely, the highest quartile of healthy and traditional dietary patterns were associated with lower odds ratio for depression among women compared with the lowest quartile. In this study traditional diet was loaded on fish and fruit consumption and healthy diet was loaded on vegetables consumption. Another finding from the SUN cohort study demonstrated an inverse relationship between the adherence to Mediterranean diet and depression, while consumption of fast foods and commercial baked goods increased the risk of depression among Spanish [115, $116]$.

Although the findings of Sugawara' study [113] did not confirm the association between dietary pattern and depression, many studies showed that diet quality is a protective factor against depression [117, 118]. Interestingly, the serum concentration of folate, as a determinant of depression, is a marker of diet quality [119]. However, many observational studies reported low diet quality among diabetic patients $[120,121]$. Additionally, because of the cumulative and synergic effect of nutrients from different dietary sources compared with the effect of one isolated nutrient, assessing the whole diet is preferred to study various nutrients, separately.

\section{Conclusion}

While depression is a common disorder among diabetic patients, which could affect the success of treatment, very limited studies were conducted among diabetic patients to treat depression. In conclusion, dietary recommendations for depression are the same for metabolic syndrome, because of the similar pathophysiology [122]. SFA, TFA, low fat diet, lower quality diets, and unhealthy dietary patterns such as western diet were associated with more depression symptoms while n-3 PUFA, MUFA, Mediterranean dietary pattern and other healthy dietary pattern which heavily characterized by fruit, vegetables, and fish were inversely associated with depressive symptoms. In present study we focused on the role of different macronutrients in treatment of depression. However, isolation of the effect of one component of nutrients from others on the endpoints is difficult. On the other hand, decreasing the proportion of a nutrient is inevitably associated with increasing the proportion of other nutrients. Hence, it is difficult to attribute outcomes to the decreased nutrient or increased one. More studies are needed to clarify the effects of replacing various nutrients (in different types, for example, vegetable or animal proteins, simple or complex carbohydrates, saturated or unsaturated fat and their dietary sources) with each other on mood and depressive symptoms. Moreover, because of various comorbidities in diabetic patients such as renal failure, neuropathy, and coronary heart diseases, the appropriate range of various macronutrients as well as the proper type of each macronutrient should be clearly defined.

\section{Acknowledgment}

This paper was granted by Isfahan University of Medical Sciences, Isfahan, Iran.

\section{References}

[1] R. J. Anderson, K. E. Freedland, R. E. Clouse, and P. J. Lustman, "The prevalence of comorbid depression in adults with diabetes: a meta-analysis," Diabetes Care, vol. 24, no. 6, pp. 1069-1078, 2001.

[2] J. Wagner, J. Tsimikas, G. Abbott, M. de Groot, and A. Heapy, "Racial and ethnic differences in diabetic patient-reported depression symptoms, diagnosis, and treatment," Diabetes Research and Clinical Practice, vol. 75, no. 1, pp. 119-122, 2007.

[3] M. M. Williams, R. E. Clouse, and P. J. Lustman, "Treating depression to prevent diabetes and its complications: understanding depression as a medical risk factor," Clinical Diabetes, vol. 24, no. 2, pp. 79-86, 2006.

[4] D. L. Musselman, E. Betan, H. Larsen, and L. S. Phillips, "Relationship of depression to diabetes types 1 and 2: epidemiology, biology, and treatment," Biological Psychiatry, vol. 54, no. 3, pp. 317-329, 2003.

[5] W. W. Eaton, "Epidemiologic evidence on the comorbidity of depression and diabetes," Journal of Psychosomatic Research, vol. 53, no. 4, pp. 903-906, 2002.

[6] N. Kawakami, N. Takatsuka, H. Shimizu, and H. Ishibashi, "Depressive symptoms and occurrence of Type 2 diabetes among Japanese men," Diabetes Care, vol. 22, no. 7, pp. 10711076, 1999.

[7] C. Arroyo, F. B. Hu, L. M. Ryan et al., "Depressive symptoms and risk of Type 2 diabetes in women," Diabetes Care, vol. 27, no. 1, pp. 129-133, 2004.

[8] M. J. Knol, J. W. R. Twisk, A. T. F. Beekman, R. J. Heine, F. J. Snoek, and F. Pouwer, "Depression as a risk factor for the onset of Type 2 diabetes mellitus. A meta-analysis," Diabetologia, vol. 49, no. 5, pp. 837-845, 2006.

[9] S. H. Golden, M. Lazo, M. Carnethon et al., "Examining a bidirectional association between depressive symptoms and diabetes," Journal of the American Medical Association, vol. 299, no. 23, pp. 2751-2759, 2008.

[10] A. Rozanski, J. A. Blumenthal, and J. Kaplan, "Impact of psychological factors on the pathogenesis of cardiovascular disease and implications for therapy," Circulation, vol. 99, no. 16, pp. 2192-2217, 1999.

[11] R. S. McIntyre, J. K. Soczynska, J. Z. Konarski et al., "Should depressive syndromes be reclassified as "metabolic syndrome type II"?” Annals of Clinical Psychiatry, vol. 19, no. 4, pp. 257264, 2007.

[12] S. D. Anton, R. L. Newton Jr., M. Sothern, C. K. Martin, T. M. Stewart, and D. A. Williamson, "Association of depression with Body Mass Index, sedentary behavior, and maladaptive eating attitudes and behaviors in 11 to 13 -year old children," Eating and Weight Disorders, vol. 11, no. 3, pp. e102-e108, 2006.

[13] W. Katon, L. Richardson, J. Russo et al., "Depressive symptoms in adolescence: the association with multiple health risk behaviors," General Hospital Psychiatry, vol. 32, no. 3, pp. 233-239, 2010. 
[14] E. Goodman and R. C. Whitaker, "A prospective study of the role of depression in the development and persistence of adolescent obesity," Pediatrics, vol. 110, no. 3, pp. 497-504, 2002.

[15] M. Von Korff, K. M. Scott, and O. Gureje, Eds., Global Perspectives on Mental-Physical Comorbidity in the WHO World Mental Health Surveys, Cambridge University Press, Cambridge, UK, 2009.

[16] A. Alvarez, J. Faccioli, M. Guinzbourg, M. M. Castex, C. Bayón, W. Masson et al., "Endocrine and inflammatory profiles in Type 2 diabetic patients with and without major depressive disorder," BMC Research Notes, vol. 6, article 61, 2013.

[17] K.-H. Ladwig, B. Marten-Mittag, H. Löwel, A. Döring, and W. Koenig, "Influence of depressive mood on the association of CRP and obesity in 3205 middle aged healthy men," Brain, Behavior, and Immunity, vol. 17, no. 4, pp. 268-275, 2003.

[18] G. Cizza, F. Eskandari, M. Coyle et al., "Plasma CRP levels in premenopausal women with major depression: a 12-month controlled study," Hormone and Metabolic Research, vol. 41, no. 8, pp. 641-648, 2009.

[19] J. B. Dixon, M. J. Hayden, G. W. Lambert et al., "Raised CRP levels in obese patients: symptoms of depression have an independent positive association," Obesity, vol. 16, no. 9, pp. 2010-2015, 2008.

[20] O. P. Almeida, K. McCaul, G. J. Hankey, P. Norman, K. Jamrozik, and L. Flicker, "Homocysteine and depression in later life," Archives of General Psychiatry, vol. 65, no. 11, pp. 1286-1294, 2008.

[21] P. J. Lustman and G. W. Harper, "Nonpsychiatric physicians' identification and treatment of depression in patients with diabetes," Comprehensive Psychiatry, vol. 28, no. 1, pp. 22-27, 1987.

[22] P. J. Lustman, L. S. Griffith, J. A. Gavard, and R. E. Clouse, "Depression in adults with diabetes," Diabetes Care, vol. 15, no. 11, pp. 1631-1639, 1992.

[23] W. Katon, E. H. B. Lin, and K. Kroenke, "The association of depression and anxiety with medical symptom burden in patients with chronic medical illness," General Hospital Psychiatry, vol. 29, no. 2, pp. 147-155, 2007.

[24] K. B. Wella, A. Stewart, R. D. Hays et al., "The functioning and well-being of depressed patients. Results from the medical outcomes study," Journal of the American Medical Association, vol. 262, no. 7, pp. 914-919, 1989.

[25] M. De Groot, R. Anderson, K. E. Freedland, R. E. Clouse, and P. J. Lustman, "Association of depression and diabetes complications: a meta-analysis," Psychosomatic Medicine, vol. 63, no. 4, pp. 619-630, 2001.

[26] R. E. Clouse, P. J. Lustman, K. E. Freedland, L. S. Griffith, J. B. McGill, and R. M. Carney, "Depression and coronary heart disease in women with diabetes," Psychosomatic Medicine, vol. 65, no. 3, pp. 376-383, 2003.

[27] P. J. Lustman, R. J. Anderson, K. E. Freedland, M. De Groot, R. M. Carney, and R. E. Clouse, "Depression and poor glycemic control: a meta-analytic review of the literature," Diabetes Care, vol. 23, no. 7, pp. 934-942, 2000.

[28] F. Talbot and A. Nouwen, "A review of the relationship between depression and diabetes in adults: is there a link?" Diabetes Care, vol. 23, no. 10, pp. 1556-1562, 2000.

[29] L. E. Egede, C. Ellis, and A. L. Grubaugh, "The effect of depression on self-care behaviors and quality of care in a national sample of adults with diabetes," General Hospital Psychiatry, vol. 31 , no. 5 , pp. $422-427,2009$.
[30] W. J. Katon, J. E. Russo, S. R. Heckbert et al., “The relationship between changes in depression symptoms and changes in health risk behaviors in patients with diabetes," International Journal of Geriatric Psychiatry, vol. 25, no. 5, pp. 466-475, 2010.

[31] P. S. Ciechanowski, W. J. Katon, and J. E. Russo, "Depression and diabetes: impact of depressive symptoms on adherence, function, and costs," Archives of Internal Medicine, vol. 160, no. 21, pp. 3278-3285, 2000.

[32] L. E. Egede, "Diabetes, major depression, and functional disability among U.S. adults," Diabetes Care, vol. 27, no. 2, pp. 421-428, 2004.

[33] W. J. Katon, C. Rutter, G. Simon et al., "The association of comorbid depression with mortality in patients with Type 2 diabetes," Diabetes Care, vol. 28, no. 11, pp. 2668-2672, 2005.

[34] X. Zhang, S. L. Norris, E. W. Gregg, Y. J. Cheng, G. Beckles, and H. S. Kahn, "Depressive symptoms and mortality among persons with and without diabetes," American Journal of Epidemiology, vol. 161, no. 7, pp. 652-660, 2005.

[35] G. Nagy, K. Rosta, B. Szémán, M. Sasvári-Székely, and A. Somogyi, "Clinical aspects of the link between diabetes and depression," Orvosi Hetilap, vol. 152, no. 13, pp. 498-504, 2011 (Hungarian).

[36] Y. Ma, B. C. Olendzki, P. A. Merriam et al., "A randomized clinical trial comparing low-glycemic index versus ADA dietary education among individuals with Type 2 diabetes," Nutrition, vol. 24, no. 1, pp. 45-56, 2008.

[37] D. M. Mwamburi, E. Liebson, M. Folstein, K. Bungay, K. L. Tucker, and W. Q. Qiu, "Depression and glycemic intake in the homebound elderly," Journal of Affective Disorders, vol. 132, no. 1-2, pp. 94-98, 2011.

[38] H. Umegaki, S. Iimuro, A. Araki et al., "Association of higher carbohydrate intake with depressive mood in elderly diabetic women," Nutritional Neuroscience, vol. 12, no. 6, pp. 267-271, 2009.

[39] T. Ciarambino, N. Ferrara, P. Castellino, G. Paolisso, L. Coppola, and M. Giordano, "Effects of a 6-days-a-week low protein diet regimen on depressive symptoms in young-old Type 2 diabetic patients," Nutrition, vol. 27, no. 1, pp. 46-49, 2011.

[40] T. Ciarambino, P. Castellino, G. Paolisso et al., "Long term effects of low protein diet on depressive symptoms and quality of life in elderly Type 2 diabetic patients," Clinical Nephrology, vol. 78, pp. 122-128, 2012.

[41] O. Stanger, B. Fowler, K. Pietrzik et al., "Homocysteine, folate and vitamin B12 in neuropsychiatric diseases: review and treatment recommendations," Expert Review of Neurotherapeutics, vol. 9, no. 9, pp. 1393-1412, 2009.

[42] M. Bot, F. Pouwer, J. Assies et al., "Eicosapentaenoic acid as an add-on to antidepressant medication for co-morbid major depression in patients with diabetes mellitus: a randomized, double-blind placebo-controlled study," Journal of Affective Disorders, vol. 126, no. 1-2, pp. 282-286, 2010.

[43] N. Michels, I. Sioen, C. Braet et al., "Stress, emotional eating behaviour and dietary patterns in children," Appetite, vol. 59, pp. 762-769, 2012.

[44] N. E. Rosenthal, M. J. Genhart, B. Caballero et al., "Psychobiological effects of carbohydrate- and protein-rich meals in patients with seasonal affective disorder and normal controls," Biological Psychiatry, vol. 25, no. 8, pp. 1029-1040, 1989.

[45] J. J. Wurtman, "Carbohydrate craving, mood changes, and obesity," Journal of Clinical Psychiatry, vol. 49, supplement, pp. 37-39, 1988. 
[46] R. J. Wurtman and J. J. Wurtman, "Carbohydrates and depression," Scientific American, vol. 260, no. 1, pp. 68-75, 1989.

[47] S. S. Runchey, M. N. Pollak, L. M. Valsta et al., "Glycemic load effect on fasting and post-prandial serum glucose, insulin, IGF-1 and IGFBP-3 in a randomized, controlled feeding study," European Journal of Clinical Nutrition, vol. 66, pp. 1146-1152, 2012.

[48] T. A. O’Sullivan, A. P. Bremner, S. O’Neill, and P. LyonsWall, "Comparison of multiple and novel measures of dietary glycemic carbohydrate with insulin resistant status in older women," Nutrition and Metabolism, vol. 7, article 25, 2010.

[49] T. A. O’Sullivan, A. P. Bremner, S. O’Neill, and P. Lyons-Wall, "Glycaemic load is associated with insulin resistance in older Australian women," European Journal of Clinical Nutrition, vol. 64, no. 1, pp. 80-87, 2010.

[50] M. Timonen, D. Horrobin, J. Jokelainen, J. Laitinen, A. Herva, and P. Räsänen, "Fish consumption and depression: the Northern Finland 1966 birth cohort study," Journal of Affective Disorders, vol. 82, no. 3, pp. 447-452, 2004.

[51] R. J. Wurtman and J. J. Wurtman, "Brain serotonin, carbohydrate-craving, obesity and depression," Obesity Research, vol. 3, supplement 4, pp. 477S-480S, 1995.

[52] J. C. Y. Louie, A. E. Buyken, J. C. Brand-Miller, and V. M. Flood, "The link between dietary glycemic index and nutrient adequacy," American Journal of Clinical Nutrition, vol. 95, no. 3, pp. 694-702, 2012.

[53] M. Y. B. Nisak, R. A. Talib, A. K. Norimah, H. Gilbertson, and K. N. Azmi, "Improvement of dietary quality with the aid of a low glycemic index diet in Asian patients with Type 2 diabetes mellitus," Journal of the American College of Nutrition, vol. 29, no. 3, pp. 161-170, 2010.

[54] N. R. Sahyoun, A. L. Anderson, F. A. Tylavsky, S. L. Jung, D. E. Sellmeyer, and T. B. Harris, "Dietary glycemic index and glycemic load and the risk of Type 2 diabetes in older adults," American Journal of Clinical Nutrition, vol. 87, no. 1, pp. 126-131, 2008.

[55] A. D. Liese, M. Schulz, F. Fang et al., "Dietary glycemic index and glycemic load, carbohydrate and fiber intake, and measures of insulin sensitivity, secretion, and adiposity in the insulin resistance atherosclerosis study," Diabetes Care, vol. 28, no. 12, pp. 2832-2838, 2005.

[56] R. J. Wurtman, J. J. Wurtman, M. M. Regan, J. M. McDermott, R. H. Tsay, and J. J. Breu, "Effects of normal meals rich in carbohydrates or proteins on plasma tryptophan and tyrosine ratios," American Journal of Clinical Nutrition, vol. 77, no. 1, pp. 128-132, 2003.

[57] E. M. Berry, J. H. Growdon, J. J. Wurtman, B. Caballero, and R. J. Wurtman, "A balanced carbohydrate:protein diet in the management of Parkinson's disease," Neurology, vol. 41, no. 8, pp. 1295-1297, 1991.

[58] C. R. Markus, "Effects of carbohydrates on brain tryptophan availability and stress performance," Biological Psychology, vol. 76, no. 1-2, pp. 83-90, 2007.

[59] A. Aparicio, F. Robles, A. M. López-Sobaler, and R. M. Ortega, "Dietary glycaemic load and odds of depression in a group of institutionalized elderly people without antidepressant treatment," European Journal of Nutrition, vol. 52, no. 3, pp. 10591066, 2013.

[60] F. N. Jacka, J. A. Pasco, A. Mykletun et al., "Diet quality in bipolar disorder in a population-based sample of women," Journal of Affective Disorders, vol. 129, no. 1-3, pp. 332-337, 2011.
[61] K. Murakami, Y. Miyake, S. Sasaki et al., "Dietary glycemic index and load and the risk of postpartum depression in Japan: the Osaka Maternal and Child Health Study," Journal of Affective Disorders, vol. 110, no. 1-2, pp. 174-179, 2008.

[62] M. M. Kogon, K. Kräuchi, P. Van Der Velde, H. Van Der Werf, and U. Keller, "Psychological and metabolic effects of dietary carbohydrates and dexfenfluramine during a low-energy diet in obese women," American Journal of Clinical Nutrition, vol. 60, no. 4, pp. 488-493, 1994.

[63] J. C. Rosen, D. A. Hunt, E. A. H. Sims, and C. Bogardus, "Comparison of carbohydrate-containing and carbohydraterestricted hypocaloric diets in the treatment of obesity: effects on appetite and mood," American Journal of Clinical Nutrition, vol. 36, no. 3, pp. 463-469, 1982.

[64] K. E. D’Anci, K. L. Watts, R. B. Kanarek, and H. A. Taylor, "Lowcarbohydrate weight-loss diets. Effects on cognition and mood," Appetite, vol. 52, no. 1, pp. 96-103, 2009.

[65] A. K. Halyburton, G. D. Brinkworth, C. J. Wilson et al., "Lowand high-carbohydrate weight-loss diets have similar effects on mood but not cognitive performance," American Journal of Clinical Nutrition, vol. 86, no. 3, pp. 580-587, 2007.

[66] G. D. Brinkworth, J. D. Buckley, M. Noakes, P. M. Clifton, and C. J. Wilson, "Long-term effects of a very low-carbohydrate diet and a low-fat diet on mood and cognitive function," Archives of Internal Medicine, vol. 169, no. 20, pp. 1873-1880, 2009.

[67] P. L. Kimmel, "Depression in patients with chronic renal disease: what we know and what we need to know," Journal of Psychosomatic Research, vol. 53, no. 4, pp. 951-956, 2002.

[68] M. Giordano, P. Tirelli, T. Ciarambino et al., "Screening of depressive symptoms in young-old hemodialysis patients: relationship between beck depression inventory and 15-item geriatric depression scale," Nephron, vol. 106, no. 4, pp. c187c192, 2007.

[69] S. S. Hedayati, H. B. Bosworth, L. P. Briley et al., "Death or hospitalization of patients on chronic hemodialysis is associated with a physician-based diagnosis of depression," Kidney International, vol. 74, no. 7, pp. 930-936, 2008.

[70] L. V. López, M. J. S. Acosta, M. V. G. Robles, M. T. Tamayo, and R. C. Limones, "Effect of protein restriction diet on renal function and metabolic control in patients with Type 2 diabetes: a randomized clinical trial," Nutricion Hospitalaria, vol. 23, no. 2, pp. 141-147, 2008.

[71] L. Azadbakht, R. Shakerhosseini, S. Atabak, M. Jamshidian, Y. Mehrabi, and A. Esmaill-Zadeh, "Beneficiary effect of dietary soy protein on lowering plasma levels of lipid and improving kidney function in type II diabetes with nephropathy," European Journal of Clinical Nutrition, vol. 57, no. 10, pp. 1292-1294, 2003.

[72] L. Azadbakht and A. Esmaillzadeh, "Soy-protein consumption and kidney-related biomarkers among Type 2 diabetics: a crossover, randomized clinical trial," Journal of Renal Nutrition, vol. 19, no. 6, pp. 479-486, 2009.

[73] L. Azadbakht, S. Atabak, and A. Esmaillzadeh, "Soy protein intake, cardiorenal indices, and C-reactive protein in Type 2 diabetes with nephropathy," Diabetes Care, vol. 31, no. 4, pp. 648-654, 2008.

[74] American Diabetes Association, "Standards of Medical Care in Diabetes 2009," Diabetes Care, vol. 32, pp. S13-S61, 2009.

[75] M. Giordano, P. Lucidi, T. Ciarambino et al., "Effects of dietary protein restriction on albumin and fibrinogen synthesis in macroalbuminuric Type 2 diabetic patients," Diabetologia, vol. 51, no. 1, pp. 21-28, 2008. 
[76] S. Eyre, P.-O. Attman, and B. Haraldsson, "Positive effects of protein restriction in patients with chronic kidney disease," Journal of Renal Nutrition, vol. 18, no. 3, pp. 269-280, 2008.

[77] S. N. Young, "The use of diet and dietary components in the study of factors controlling affect in humans: a review," Journal of Psychiatry \& Neuroscience, vol. 18, no. 5, pp. 235-244, 1993.

[78] G. Hayward, G. M. Goodwin, P. J. Cowen, and C. J. Harmer, "Low-dose tryptophan depletion in recovered depressed patients induces changes in cognitive processing without depressive symptoms," Biological Psychiatry, vol. 57, no. 5, pp. 517-524, 2005.

[79] D. Benton and R. T. Donohoe, "The effects of nutrients on mood," Public Health Nutrition, vol. 2, no. 3 A, pp. 403-409, 1999.

[80] A. R. Wolfe, C. Arroyo, S. H. Tedders, Y. Li, Q. Dai, and J. Zhang, "Dietary protein and protein-rich food in relation to severely depressed mood: a 10year follow-up of a national cohort," Progress in Neuro-Psychopharmacology and Biological Psychiatry, vol. 35, no. 1, pp. 232-238, 2011.

[81] S. G. Lemmens, J. M. Born, E. A. Martens, M. J. Martens, and M. S. Westerterp-Plantenga, "Influence of consumption of a high-protein vs. high- carbohydrate meal on the physiological cortisol and psychological mood response in men and women," PLoS One, vol. 6, no. 2, Article ID e16826, 2011.

[82] T. Decsi, É. Szabó, I. Burus et al., "Low contribution of n-3 polyunsaturated fatty acids to plasma and erythrocyte membrane lipids in diabetic young adults," Prostaglandins Leukotrienes and Essential Fatty Acids, vol. 76, no. 3, pp. 159164, 2007.

[83] K. M. Appleton, P. J. Rogers, and A. R. Ness, "Updated systematic review and meta-analysis of the effects of n-3 long-chain polyunsaturated fatty acids on depressed mood," American Journal of Clinical Nutrition, vol. 91, no. 3, pp. 757-770, 2010.

[84] J. Assies, F. Pouwer, A. Lok et al., "Plasma and erythrocyte fatty acid patterns in patients with recurrent depression: a matched case-control study," PLoS One, vol. 5, no. 5, p. e10635, 2010.

[85] A. K. B. Van Reedt Dortland, E. J. Giltay, T. Van Veen, J. Van Pelt, F. G. Zitman, and B. W. J. H. Penninx, "Associations between serum lipids and major depressive disorder: results from the Netherlands Study of Depression and Anxiety (NESDA)," Journal of Clinical Psychiatry, vol. 71, no. 6, pp. 729-736, 2010.

[86] B. Vergès, "Lipid disorders in type 1 diabetes," Diabetes and Metabolism, vol. 35, no. 5, pp. 353-360, 2009.

[87] R. M. Krauss and P. W. Siri, "Dyslipidemia in Type 2 diabetes," Medical Clinics of North America, vol. 88, no. 4, pp. 897-909, 2004.

[88] B. K. Puri, "Cardiovascular disease and depression: the PUFA connection," International Journal of Clinical Practice, vol. 62, no. 3, pp. 355-357, 2008.

[89] K. M. Appleton, J. V. Woodside, J. W. G. Yarnell et al., "Depressed mood and dietary fish intake: direct relationship or indirect relationship as a result of diet and lifestyle?" Journal of Affective Disorders, vol. 104, no. 1-3, pp. 217-223, 2007.

[90] J. R. Hibbeln, "Fish consumption and major depression," Lancet, vol. 351, no. 9110, article 1213, 1998.

[91] P. B. Adams, S. Lawson, A. Sanigorski, and A. J. Sinclair, "Arachidonic acid to eicosapentaenoic acid ratio in blood correlates positively with clinical symptoms of depression," Lipids, vol. 31, no. 3, pp. S157-S161, 1996.

[92] R. Edwards, M. Peet, J. Shay, and D. Horrobin, "Omega-3 polyunsaturated fatty acid levels in the diet and in red blood cell membranes of depressed patients," Journal of Affective Disorders, vol. 48, no. 2-3, pp. 149-155, 1998.

[93] C. Féart, E. Peuchant, L. Letenneur et al., "Plasma eicosapentaenoic acid is inversely associated with severity of depressive symptomatology in the elderly: data from the Bordeaux sample of the Three-City Study," American Journal of Clinical Nutrition, vol. 87, no. 5, pp. 1156-1162, 2008.

[94] J. G. Martins, "EPA but not DHA appears to be responsible for the efficacy of omega-3 long chain polyunsaturated fatty acid supplementation in depression: evidence from a meta-analysis of randomized controlled trials," Journal of the American College of Nutrition, vol. 28, no. 5, pp. 525-542, 2009.

[95] R. J. Mocking, J. Assies, M. Bot, E. H. Jansen, A. H. Schene, and F. Pouwer, "Biological effects of add-on eicosapentaenoic acid supplementation in diabetes mellitus and co-morbid depression: a randomized controlled trial," PLoS One, vol. 7, Article ID e49431, 2012.

[96] A. Sánchez-Villegas, L. Verberne, J. de Irala et al., "Dietary fat intake and the risk of depression: the SUN project," PLoS One, vol. 6, no. 1, Article ID e16268, 2011.

[97] B. A. Golomb, M. A. Evans, H. L. White, and J. E. Dimsdale, "Trans fat consumption and aggression," PLoS One, vol. 7, no. 3, Article ID e32175, 2012.

[98] K. Murakami, Y. Miyake, S. Sasaki, K. Tanaka, and M. Arakawa, "Fish and n-3 polyunsaturated fatty acid intake and depressive symptoms: ryukyus child health study," Pediatrics, vol. 126, no. 3, pp. e623-e630, 2010.

[99] A. L. Suominen-Taipale, T. Partonen, A. W. Turunen, S. Männistö, A. Jula, and P. K. Verkasalo, "Fish consumption and omega-3 polyunsaturated fatty acids in relation to depressive episodes: a cross-sectional analysis," PLoS One, vol. 5, no. 5, p. e10530, 2010.

[100] A. M. Rizzo, P. A. Corsetto, G. Montorfano, A. Opizzi, M. Faliva, A. Giacosa et al., "Comparison between the AA/EPA ratio in depressed and non depressed elderly females: omega-3 fatty acid supplementation correlates with improved symptoms but does not change immunological parameters," Nutrition Journal, vol. 11, article 82, 2012.

[101] E. Kesse-Guyot, M. Touvier, V. A. Andreeva et al., "Crosssectional but not longitudinal association between n-3 fatty acid intake and depressive symptoms: results from the SU.VI.MAX 2 study," American Journal of Epidemiology, vol. 175, no. 10, pp. 979-987, 2012.

[102] P. J. Rogers, K. M. Appleton, D. Kessler et al., "No effect of n-3 long-chain polyunsaturated fatty acid (EPA and DHA) supplementation on depressed mood and cognitive function: a randomised controlled trial," British Journal of Nutrition, vol. 99, no. 2, pp. 421-431, 2008.

[103] Y. Park, M. Kim, D. Baek, and S. H. Kim, "Erythrocyte n-3 polyunsaturated fatty acid and seafood intake decrease the risk of depression: case-control study in Korea," Annals of Nutrition and Metabolism, vol. 61, no. 1, pp. 25-31, 2012.

[104] S. Hayley, M. O. Poulter, Z. Merali, and H. Anisman, "The pathogenesis of clinical depression: stressor- and cytokineinduced alterations of neuroplasticity," Neuroscience, vol. 135, no. 3, pp. 659-678, 2005.

[105] H. Anisman, "Cascading effects of stressors and inflammatory immune system activation: implications for major depressive disorder," Journal of Psychiatry and Neuroscience, vol. 34, no. 1, pp. 4-20, 2009.

[106] F. Karege, G. Vaudan, M. Schwald, N. Perroud, and R. La Harpe, "Neurotrophin levels in postmortem brains of suicide victims 
and the effects of antemortem diagnosis and psychotropic drugs," Molecular Brain Research, vol. 136, no. 1-2, pp. 29-37, 2005.

[107] S. Guo, W. J. Kim, J. Lok et al., "Neuroprotection via matrixtrophic coupling between cerebral endothelial cells and neurons," Proceedings of the National Academy of Sciences of the United States of America, vol. 105, no. 21, pp. 7582-7587, 2008.

[108] J. A. Wagner, H. Tennen, G. A. Mansoor, and G. Abbott, "History of major depressive disorder and endothelial function in postmenopausal women," Psychosomatic Medicine, vol. 68, no. 1, pp. 80-86, 2006.

[109] J. M. Bourre, "Effects of nutrients (in food) on the structure and function of the nervous system: update on dietary requirements for brain. Part 2: macronutrients," Journal of Nutrition, Health and Aging, vol. 10, no. 5, pp. 386-399, 2006.

[110] A. C. Logan, "Omega-3 and depression research: hold the olive oil," Prostaglandins Leukotrienes and Essential Fatty Acids, vol. 72, no. 6, 441 pages, 2005.

[111] H. Konttinen, S. Männistö, S. Sarlio-Lähteenkorva, K. Silventoinen, and A. Haukkala, "Emotional eating, depressive symptoms and self-reported food consumption. A populationbased study," Appetite, vol. 54, no. 3, pp. 473-479, 2010.

[112] T. N. Akbaraly, E. J. Brunner, J. E. Ferrie, M. G. Marmot, M. Kivimaki, and A. Singh-Manoux, "Dietary pattern and depressive symptoms in middle age," British Journal of Psychiatry, vol. 195, no. 5, pp. 408-413, 2009.

[113] N. Sugawara, N. Yasui-Furukori, S. Tsuchimine et al., "No association between dietary patterns and depressive symptoms among a community-dwelling population in Japan," Annals of General Psychiatry, vol. 11, article 24, 2012.

[114] A. Le Port, A. Gueguen, E. Kesse-Guyot et al., "Association between dietary patterns and depressive symptoms over time: a 10-year follow-up study of the GAZEL cohort," PLoS One, vol. 7, Article ID e51593, 2012.

[115] A. Sánchez-Villegas, M. Delgado-Rodríguez, A. Alonso et al., "Association of the Mediterranean dietary pattern with the incidence of depression: the Seguimiento Universidad de Navarra/University of Navarra follow-up (SUN) cohort," Archives of General Psychiatry, vol. 66, no. 10, pp. 1090-1098, 2009.

[116] A. Sánchez-Villegas, E. Toledo, J. De Irala, M. Ruiz-Canela, J. Pla-Vidal, and M. A. Martínez-González, "Fast-food and commercial baked goods consumption and the risk of depression," Public Health Nutrition, vol. 15, no. 3, pp. 424-432, 2012.

[117] T. N. Akbaraly, S. Sabia, M. J. Shipley, G. D. Batty, and M. Kivimaki, "Adherence to healthy dietary guidelines and future depressive symptoms: evidence for sex differentials in the Whitehall II study," The American Journal of Clinical Nutrition, vol. 97, pp. 419-427, 2013.

[118] F. N. Jacka, J. A. Pasco, A. Mykletun et al., "Association of western and traditional diets with depression and anxiety in women," American Journal of Psychiatry, vol. 167, no. 3, pp. 305311, 2010.

[119] A. Nanri, H. Hayabuchi, M. Ohta, M. Sato, N. Mishima, and T. Mizoue, "Serum folate and homocysteine and depressive symptoms among Japanese men and women," European Journal of Clinical Nutrition, vol. 64, no. 3, pp. 289-296, 2010.

[120] L. De Koning, S. E. Chiuve, T. T. Fung, W. C. Willett, E. B. Rimm, and F. B. Hu, "Diet-quality scores and the risk of Type 2 diabetes in men," Diabetes Care, vol. 34, no. 5, pp. 1150-1156, 2011.

[121] T. T. Fung, M. McCullough, R. M. Van Dam, and F. B. Hu, "A prospective study of overall diet quality and risk of Type 2 diabetes in women," Diabetes Care, vol. 30, no. 7, pp. 1753-1757, 2007.

[122] A. Sanchez-Villegas and M. A. Martínez-González, "Diet, a new target to prevent depression?” BMC Medicine, vol. 11, article 3, 2013. 


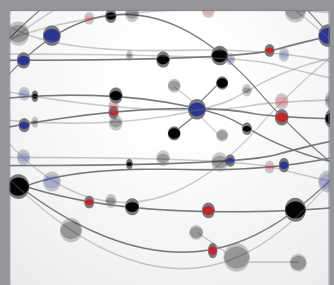

The Scientific World Journal
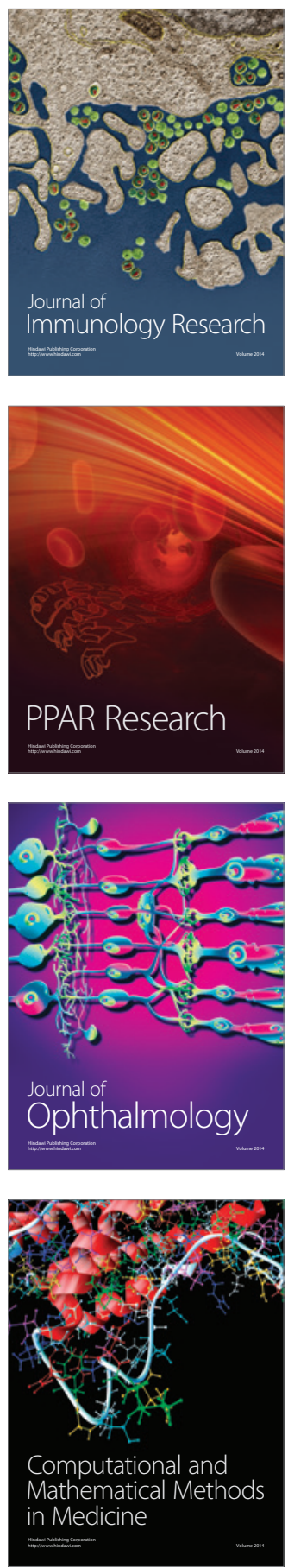

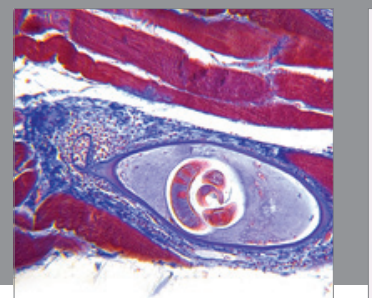

Gastroenterology

Research and Practice
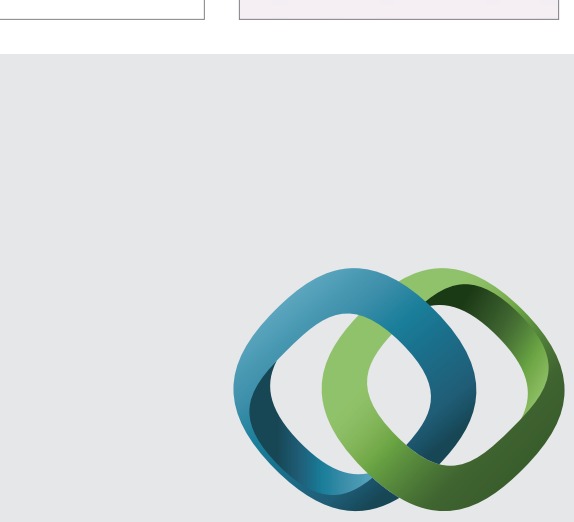

\section{Hindawi}

Submit your manuscripts at

http://www.hindawi.com
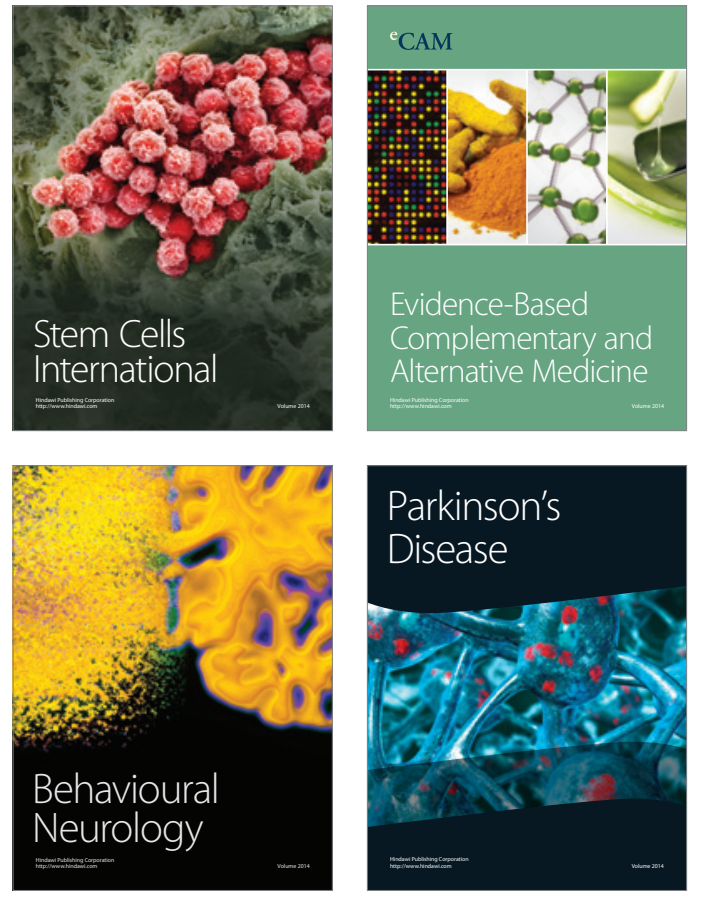
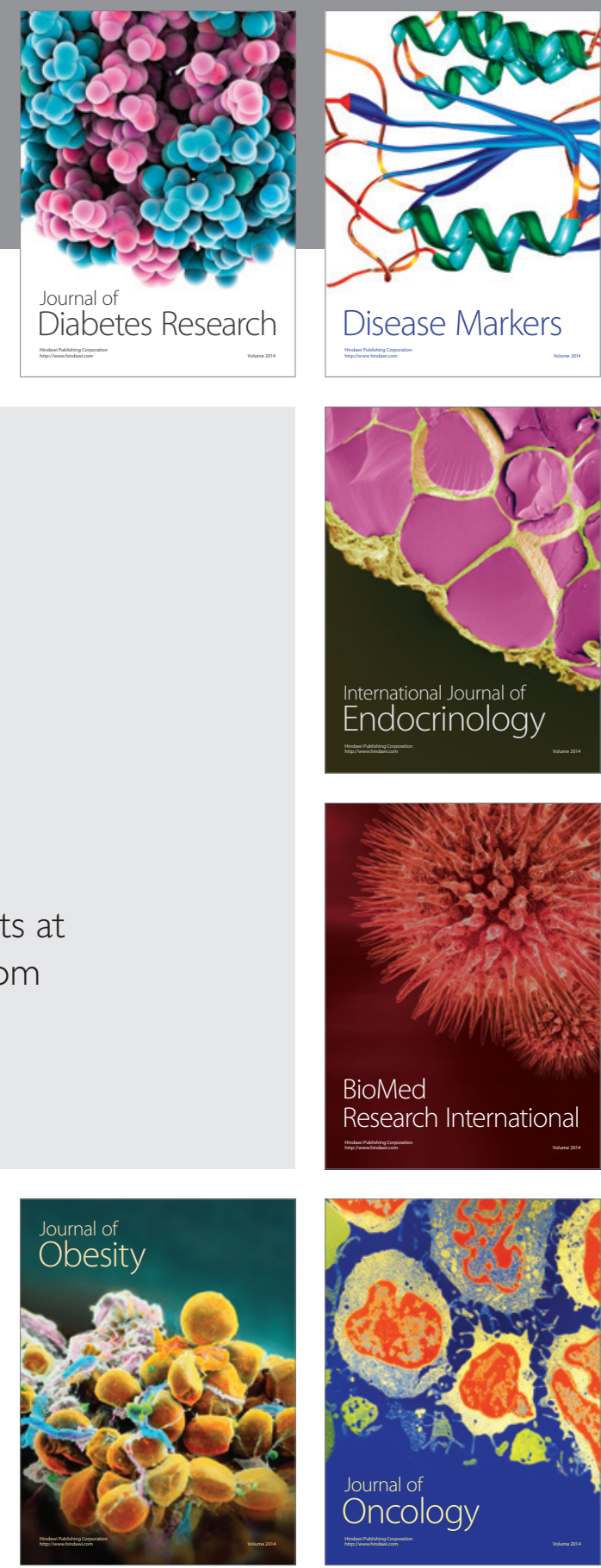

Disease Markers
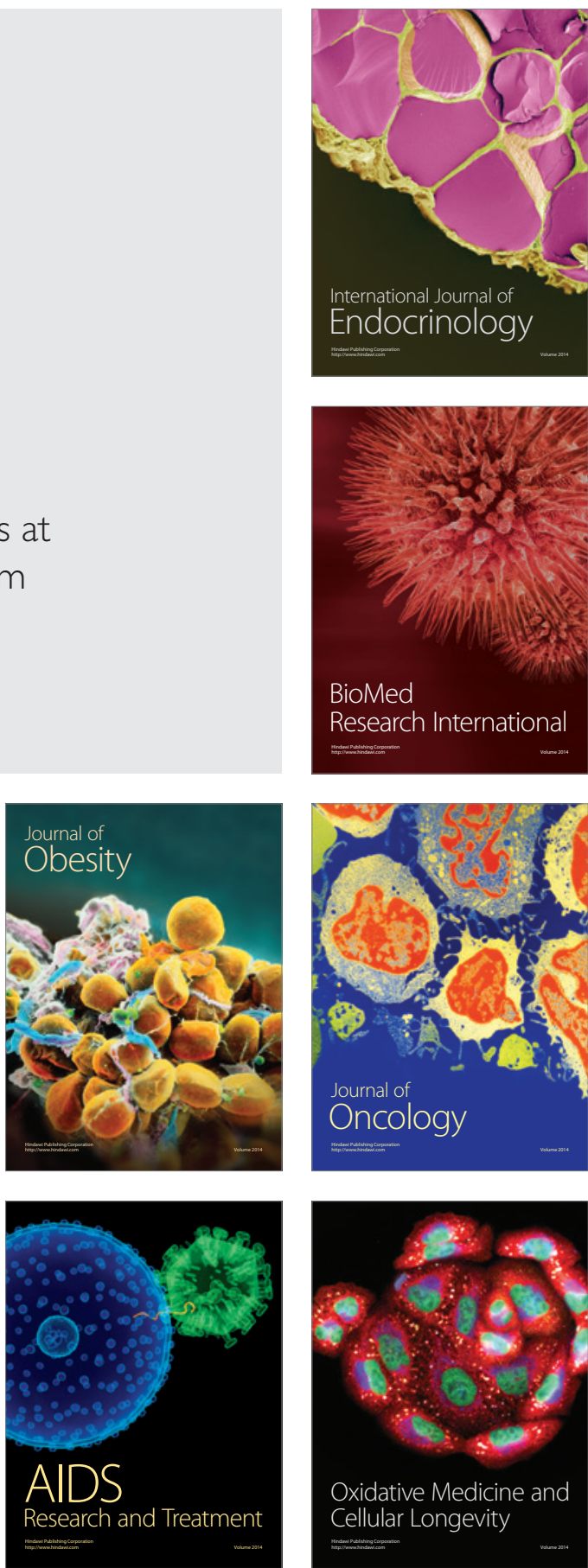